\title{
The effect of type of anesthesia on intra-and postoperative blood loss at elective cesarean section
}

\author{
Jeong Eun Kim, Ji Hyang Lee, Eun Ju Kim, Myung Woo Min, Jong Seouk Ban, and Sang Gon Lee \\ Department of Anesthesiology and Pain Medicine, Daegu Fatima Hospital, Daegu, Korea
}

Background: In cesarean section (c-sec) it is known that women receiving spinal anesthesia have decreased intraoperative blood loss compared to women receiving general anesthesia. However, we should always consider postoperative bleeding (postpartum bleeding) that may follow. The amount of postpartum bleeding can be substantial. Therefore, we sought to evaluate the effect of type of anesthesia retrospectively on intra- and postoperative blood loss by comparing the changes of postoperative Hb, Hct at c-sec.

Methods: We retrospectively compared the medical records of 287 elective c-sec patients. We excluded medical and obstetric conditions that may predispose such patients to increased blood loss. Subsequent detailed record analysis included 152 patients that received spinal anesthesia (group S), and 135 patients that received sevoflurane for general anesthesia (group G).

Results: In comparison with the preoperative $\mathrm{Hb}$, rates of $\mathrm{Hb}$ in the $1^{\text {st }}$ postoperative day in group S significantly decreased compared to group G, but there was no significant difference in decreasing rates of $\mathrm{Hb}$ in the $3^{\text {rd }}$ postoperative day between groups S and G. Estimated blood loss (EBL) of the intraoperative and operative day in group S was significantly lower compared to group G, but there was no significant difference in EBL of $1^{\text {st }}$ and $2^{\text {nd }}$ postoperative day between groups S and G.

Conclusions: We conclude that group S had a decrease in blood loss between the intraoperative and operative day and there was no significant differences in postoperative blood loss compared with group G. (Korean J Anesthesiol 2012; 62: 125-129)

Key Words: Blood loss, Cesarean section, General anesthesia, Hemoglobin, Spinal anesthesia.

Received: April 12, 2011. Revised: 1st, June 9, 2011; 2nd, August 1, 2011. Accepted: September 19, 2011.

Corresponding author: Ji Hyang Lee, M.D., Department of Anesthesiology and Pain Medicine, Daegu Fatima Hospital, 302-1, Shinam-dong, Dong-gu, Daegu 701-010, Korea. Tel: 82-53-940-7433, Fax: 82-53-940-7434, E-mail: lovehan3@yahoo.co.kr

(c) This is an open-access article distributed under the terms of the Creative Commons Attribution Non-Commercial License (http:// creativecommons.org/licenses/by-nc/3.0/), which permits unrestricted non-commercial use, distribution, and reproduction in any medium, provided the original work is properly cited. 


\section{Introduction}

In the 1950s, spinal anesthesia (SA) was regarded as the most dangerous anesthesia for pregnant women [1]. In recent times, however, it has been preferred in many countries, and instruments and drugs have been remarkably advanced. This is because SA tends to be superior to general anesthesia (GA) in airway management and intraoperative blood loss in the process of cesarean section (c-sec) [2-5]. However, there has been no comparison between the two in postoperative blood loss. For reference, the c-sec tends to cause one-month postoperative hemorrhage.

Hereat et al. made a comparison between women that underwent plain c-sec under sevoflurane-based GA (group G) and women that underwent $0.5 \%$ bupivacaine-based SA (group $\mathrm{S}$ ) in postoperative hemoglobin ( $\mathrm{Hb}$ ) and hematocrit (Hct), and investigated how anesthesia types would influence the estimated blood loss (EBL) during and after surgery.

\section{Materials and Methods}

This study was conducted on patients who underwent c-sec between January 2005 and December 2009 at our hospital, excluding cases of internal fundamental diseases, pregnancy-related complications, anemia (Hb: $9.0 \mathrm{mg} / \mathrm{dl}$ and less), hydramnion, preterm deliveries, fetal deformities, malpresentation, uterine myomas, twin pregnancy, failed induction of labor and fetal distress syndromes. The surgeries were performed by two obstetricians having over ten years' experience, and the research data were collected from the medical records of patients.

Out of 537 patients who underwent c-sec during the period, 287 were used as subjects in this study. The group $S$ and the group G were composed of 152 and 135 patients respectively. On all the cases, c-sec were performed in the same procedure, i,e., an incision in the lower abdomen and a section in the uterine body. In the case of the group G, $0.2 \mathrm{mg}$ of glycopyrrolate was administered by intramuscular injection 30 minutes before admission to the operating room, and 0.5 $\mathrm{mg} / \mathrm{kg}$ of $1 \%$ lidocaine, $2 \mathrm{mg} / \mathrm{kg}$ of propofol and 0.6 to $0.8 \mathrm{mg} /$ $\mathrm{kg}$ of rocuronium were administered immediately before the surgery. The intraoperative anesthesia was maintained by 2 $\mathrm{L} /$ min of nitrous oxide $\left(\mathrm{N}_{2} \mathrm{O}\right), 2 \mathrm{~L} / \mathrm{min}$ of oxygen $\left(\mathrm{O}_{2}\right)$ and 1 to $1.5 \mathrm{vol} \%$ of sevoflurane. In the case of the group S, 8 to $10 \mathrm{mg}$ of $0.5 \%$ bupivacaine and 15 to $20 \mu \mathrm{g}$ of fentanyl were mixed and injected to block the anesthesia of dermatomes, T4 to T6. Ephedrine or atropine was injected in cases where hypotension or bradycardia occurred after SA. In all the groups, $100 \mu \mathrm{g}$ of carbetocin was administered by intravenous injection after placental delivery. After undergoing the c-sec the patient was given an injection of 20 units of oxytocin mixed with 1,000 ml of $5 \%$ dextrose in water, and was given the fluid for one day. On the first day after surgery, a decision was made whether to transfuse blood or to inject ferric hydroxide sucrose complex (FHSC). FHSC was intravenously administered only to patients whose $\mathrm{Hb}$ was $10 \mathrm{mg} / \mathrm{dl}$ on the follow-up blood test and whose vital signs were within the normal range. However, this study did not address the time points of injections. The intraoperative transfusion was performed on patients whose preoperative $\mathrm{Hb}$ was 9 to $10 \mathrm{mg} / \mathrm{dl}$ and who were in an unstable condition hemodynamically at the anesthesiologist's discretion.

From medical records, data on age, weight, birth history, preoperative intake of iron supplements, dose of fluid in intraoperative and the recovery room, dose of postoperative fluid in the ward, time required from the beginning of the surgery to fetal delivery (birth time), time required from the induction of anesthesia to the completion of surgery (surgery time), mean of systolic and diastolic blood pressure measured from the induction of anesthesia until 5 minutes after fetal delivery (intraoperative pressure), surgical history and intravenous injection of FHSC were collected. In addition, $\mathrm{Hb}$ and Hct were measured before the surgery (POD 0), on the first day after the surgery (POD 1), and on the third day after surgery (POD 3). Comparisons were made between POD 0 and POD 1 levels, as well as between POD 1 and POD 3 levels. The patients who received transfusions were excluded from the calculation, because transfusions may affect $\mathrm{Hb}$ and Hct. Intraoperative blood losses were measured by various hands and thus had a large margin of error, hence EBL was calculated by the following formula in the light of hemodilution.

Maternal blood volume $(\mathrm{MBV})=\{0.75 \times[$ (maternal height $($ inch $) \times 50)+($ maternal weight (pound $) \times 25)] / 1,000\}(\mathrm{L})[6]$ $\mathrm{EBL}=\mathrm{MBV} \times \ln (\mathrm{POD} 0 \mathrm{Hb} / \mathrm{POD} 1 \mathrm{Hb})[7]$

*POD 0-1 Hb DR $=($ POD $0 \mathrm{Hb}-\mathrm{POD} 1 \mathrm{Hb}) / \mathrm{POD} 0 \mathrm{Hb} \times$ $100(\%)$

*POD 0-1 Hb DR: The decreasing rate of $\mathrm{Hb}$ measured before and on the first day after the surgery

EBLs were calculated during (D-EBL) and immediately after the surgery (IO-EBL), on the basis of POD $0 \mathrm{Hb}$ and POD $1 \mathrm{Hb}$. Likewise, POD 1 EBL and POD 2 EBL were calculated on the basis of POD $1 \mathrm{Hb}$ and POD $3 \mathrm{Hb}$.

PASW (SPSS) 18 was used for statistical analysis, and the Levene's test confirmed equal variance. The foregoing data on medical records were analyzed through the independent $t$ test. Intergroup comparisons were conducted in relation to DR, EBL (independent $\mathrm{t}$ test), transfusional frequency (Chi-square test) and mean transfusion volume (Mann-Whitney U test).

All the values were within mean and standard deviation (SD) 
Table 1. Selected Maternal Demographic Characteristics, Operative Time, Fluid Volume, Blood Pressure in Patients Undergoing Spinal Anesthesia versus General Anesthesia

\begin{tabular}{|c|c|c|c|}
\hline Variable & $\begin{array}{c}\text { Group SA } \\
(\mathrm{n}=152)\end{array}$ & $\begin{array}{l}\text { Group GA } \\
(\mathrm{n}=135)\end{array}$ & Comparison \\
\hline Age (yr) & $31.5 \pm 3.8$ & $32.7 \pm 6.9$ & NS \\
\hline Weight (kg) & $68.8 \pm 9.2$ & $68.6 \pm 9.3$ & NS \\
\hline \multicolumn{4}{|l|}{ Fluid volume $(\mathrm{ml})$} \\
\hline Intraoperative & $1,170.4 \pm 367.7$ & $865.6 \pm 463.2$ & $\mathrm{P}<0.01$ \\
\hline Postoperative & $5,088.8 \pm 913.0$ & $4,483.7 \pm 941.0$ & $\mathrm{P}<0.01$ \\
\hline \multicolumn{4}{|l|}{ Time (min) } \\
\hline From incision to placenta delivery & $5.8 \pm 2.2$ & $5.4 \pm 1.8$ & NS \\
\hline From incision to skin suture & $39.7 \pm 1.2$ & $38.9 \pm 1.4$ & NS \\
\hline \multicolumn{4}{|l|}{$\mathrm{BP}(\mathrm{mmHg})$} \\
\hline Systolic & $115.1 \pm 13.4$ & $145.3 \pm 13.7$ & $P=0.01$ \\
\hline Diastolic & $64.6 \pm 9.7$ & $78.70 \pm 10.0$ & $\mathrm{P}<0.01$ \\
\hline Parity (numbers) & $1.9 \pm 0.8$ & $1.75 \pm 0.7$ & $\mathrm{P}=0.036$ \\
\hline Transfusion (numbers) & $8(5.3 \%)$ & $15(11.1 \%)$ & NS \\
\hline Transfusion volume (ml) & $282.9 \pm 96.2$ & $350.5 \pm 72.9$ & NS \\
\hline Intravenous $\mathrm{Fe}$ & $69(47.9 \%)$ & $61(50.8 \%)$ & \\
\hline
\end{tabular}

Values are the Mean \pm SD. SA: spinal anesthesia, GA: general anesthesia, BP: blood pressure.

Table 2. Change of Hemoglobin and Hematocrit (Except Transfusion Group)

\begin{tabular}{lccc}
\hline Variable & $\begin{array}{c}\text { Group SA } \\
(\mathrm{n}=144)\end{array}$ & $\begin{array}{c}\text { Group GA } \\
(\mathrm{n}=120)\end{array}$ & Comparison \\
\hline DR Hb (POD 0-POD 1) (\%) & $9.9 \pm 8.8$ & $13.5 \pm 9.4$ & $\mathrm{P}=0.001$ \\
DR Hb (POD 0-POD 3) (\%) & $19.4 \pm 10.0$ & $21.4 \pm 9.4$ & NS \\
DR Hb (POD 1-POD 3) (\%) & $10.5 \pm 7.7$ & $9.0 \pm 7.7$ & NS \\
DR Hct (POD 0-POD 1) (\%) & $8.3 \pm 9.1$ & $12.6 \pm 10.7$ & $\mathrm{P}<0.001$ \\
DR Hct (POD 0-POD 3) (\%) & $17.6 \pm 9.4$ & $20.0 \pm 10.6$ & $\mathrm{P}=0.044$ \\
DR Hct (POD 1-POD 3) (\%) & $10.0 \pm 7.8$ & $8.3 \pm 7.4$ & NS \\
\hline
\end{tabular}

Values are the Mean \pm SD. SA: spinal anesthesia, GA: general anesthesia, DR: decreasing rate, Hb: hemoglobin, POD 0: preoperative, POD: postoperative day.

(mean $\pm \mathrm{SD}$ ). The significance level was defined as where the $P$ value was less than 0.05 .

\section{Results}

Table 1 shows factors that may affect the characteristics or blood losses of the groups. There were no significant intergroup differences in age, weight, fetal delivery time and surgery time. The S group showed significantly higher values in postoperative fluid dose and birth history, but showed a significantly higher value in intraoperative blood pressure.

In POD $0-1 \mathrm{Hb}$ DR, POD $0-1$ Hct DR and POD $0-3 \mathrm{Hct}$ $\mathrm{DR}$, the group $\mathrm{S}$ showed significantly lower values. In POD $0-3$ $\mathrm{Hb}$, however, there was no significant intergroup difference (Table 2). Also, in POD 1-3 Hb DR and POD 1-3 Hct DR, no significant intergroup differences were observed (Table 2).

In relation to IO-EBL and D-EBL, the group $S$ sowed significantly lower values. In D-1 EBL and D2-EBL, however, there were no significant intergroup differences (Table 3). In the
Table 3. Estimated Blood Loss in Patient Spinal Anesthesia Versus General Anesthesia (Except Transfusion Group)

\begin{tabular}{lrrc}
\hline \multicolumn{1}{c}{ Variable } & $\begin{array}{r}\text { Group SA } \\
(\mathrm{n}=144)\end{array}$ & $\begin{array}{c}\text { Group GA } \\
(\mathrm{n}=120)\end{array}$ & Comparison \\
\hline EBL (ml): D \& IO & $570 \pm 520$ & $790 \pm 570$ & $\mathrm{P}=0.001$ \\
EBL (ml): POD 1, 2 & $508 \pm 417$ & $594 \pm 480$ & NS \\
EBL (ml): Total & $1,160 \pm 710$ & $1,230 \pm 650$ & NS \\
\hline
\end{tabular}

Values are the Mean \pm SD. SA: spinal anesthesia, GA: general anesthesia, EBL: estimated blood loss, D: During intraoperative, IO: immediately after surgery, POD $1,2: 1^{\text {st }}, 2^{\text {nd }}$ postoperative day, Total: from operative day to $2^{\text {nd }}$ postoperative day.

S group, 8 (5.3\%) out of 152 patients received intraoperative or postoperative transfusions, whereas in the group G, 15 (11.1\%) out of 135 patients received them. However, there was no significant intergroup difference. Additionally, the groups did not show a significant difference in transfusion volume (Table 1).

\section{Discussion}

The group S had significantly lower values in relation to IOEBL and D-EBL, which can be explained by three reasons. First, in the case of the group S, blood is diluted in the process of fluid loading. In the case of SA, the fluid load is usually adjusted at 10 to $15 \mathrm{ml} / \mathrm{Kg}$ in order to prevent hypotension. The injected fluid mostly runs through blood vessels until childbirth and placental delivery, and thus the erythrocyte loss decreases during the surgery [2]. In this study, the intraoperative fluid doses were $1,170 \pm 367.70 \mathrm{ml}$ and $865.56 \pm 463.22 \mathrm{ml}$ in the group $\mathrm{S}$ and the group $\mathrm{G}$ respectively $(\mathrm{P}<0.01)$.

Second, intraoperative hypotension can be a reason. Richman et al. [5] conducted meta-analyses on randomized 
and controlled clinical trials to compare SA, epidural anesthesia (EA) and GA in intraoperative blood loss. Their meta-analyses were focused on all the cases of surgeries that involved GA or SA, e.g., c-sec, general surgical and orthopedic operations. The results showed that SA or EA was more effective to reduce blood loss compared to GA or the combination of GA and EA ( $\mathrm{SA} \leq$ $\mathrm{EA}<\mathrm{GA} \leq \mathrm{GA}-\mathrm{EA})$. According to their explanation, SA caused sympathetic block and vasodilatation, and thus the venous return decreased. Then, as central venous pressure dropped, the peripheral vascular resistance became lower, and as a result, the blood pressure dropped. In addition, the reduction of the intraoperative blood loss reduced the need for transfusions and reduced the onset of transfusion-related diseases. Similarly in this study, systolic and diastolic blood pressures were significantly lower in the group $\mathrm{S}$ (systolic pressure: $\mathrm{P}=0.01$ / diastolic pressure: $\mathrm{P}<0.01$ ), which may affect $\mathrm{EBL}$.

Lastly, uterine contraction may vary in different types of anesthesia. Guay [4] mentioned that in the process of c-sec, inhalation anesthetics caused uterine contractions that are closely related to postpartum hemorrhage. Various studies have been conductedon on this, and the results have showed that not only previous anesthetics such as halothane $[8,9]$ but recent ones such as desflurane [8] and sevoflurane [9-11] hinder uterine contraction.

Turner et al. [12] extracted uterine muscles after c-sec and investigated how much sevoflurane and desflurane would hinder uterine contractions. They hinder the contractions of uterine muscles at 0.5 MAC, 1 MAC and 1.5 MAC, respectively, and they were similar in extent to each other.

Oxytocin is known to be a hormone that arouses uterine contraction [13]. In surgery, oxytocin is artificially injected to arouse uterine contraction, which means that it may be important to ascertain whether sevoflurane and desflurane hinder uterine contraction induced by oxytocin. Yildiz et al. [14] conducted experiments to evaluate this. Uterine muscles, extracted after placental delivery, were exposed to oxytocin, into which sevoflurane and desflurane were injected in different concentrations. The results showed that at 0.5 MAC, 1 MAC and 2 MAC, the two hindered the frequency and amplitude of uterine contraction induced by oxytocin in proportion to their doses. At $1 \mathrm{MAC}$, on the other hand, desflurane reduced the amplitude less than sevoflurane. Consequently, they recommended that sevoflurane and desflurane be used at 0.5 MAC and 1 MAC respectively. In addition to inhalation anesthetics, intravenous anesthetics such as propofol, ketamine and midazolam hinder uterine contraction [15]. Also, there is a report that oxytocin prevents propofol from hindering uterine contraction [16]. In this study, 1 to $1.5 \mathrm{vol} \%$ of sevoflurane, $2 \mathrm{~L} /$ min of nitrous oxide $\left(\mathrm{N}_{2} \mathrm{O}\right)$ and $2 \mathrm{~L} / \mathrm{min}$ of oxygen $\left(\mathrm{O}_{2}\right)$ were used to maintain general anesthesia, inter alia, sevoflurane is deemed to hinder uterine contraction. Meanwhile, there are opinions that the intraoperative blood loss varies in different types of anesthesia.

Hood and Holubec [17] compared halothane-based GA and EA performed for $\mathrm{c}-\mathrm{sec}$, and reported that there was no significant difference in the two groups. Their study was conducted retrospectively, and was intended for halothane similar to sevoflurane in the hindrance level to uterine contraction [18]. Moreover, their study was similar in subjects to this study. However, overall their study differs from this study. Their study focused on EA with the same doses of fluids, and calculated blood losses in actual measurement values. Due to the nature of a retrospective study, their calculation may not be accurate.

Wong et al. [19] compared two groups that underwent radical prostatectomies. They reported that there was no significant intergroup difference, and that blood losses were influenced by surgical skill and surgery time rather than anesthesia types, which presents a great contrast to this study. In the case of radical prostatectomy, the target nerve to be blocked is lower than that of c-sec; hence, the blood pressure is higher but the fluid load is lower. Therefore, their study could not deal with uterine contraction that influences hemorrhage. In this study, factors presented by Wong et al. [19] were taken into consideration to specifically to minimize variables in surgical skill and surgery time, and this study was limited to c-sec performed by two obstetricians having over ten years' experience.

In relation to POD $0-1 \mathrm{Hb} \mathrm{DR}$, the group S showed a significantly lower value. But in relation to POD $0-3 \mathrm{Hb} \mathrm{DR}$, there was no significant intergroup difference. This suggests a possibility that the two groups showed different blood losses during the surgery due to anesthesia type and other factors, but that the difference narrows with time after the surgery. There were no significant intergroup differences in POD 1-3 Hb DR and POD 1-3 Hct DR, as shown in Table 2. It is known that after a c-sec, the blood loss usually reaches 200 to $300 \mathrm{ml}$ $[20,21]$. In relation to IO-EBL and D-EBL, the group $S$ showed significantly lower values. In POD 1- and POD 2 EBL, there were no significant intergroup differences. The situation was the same in POD 2 EBL (Table 3), which implies that the two groups are not different from each other in postpartum hemorrhage and hematologic recovery. It takes $\mathrm{Hb} 7$ to 28 days to return to normal [22]. Thus, it is important to conduct blood tests on the 7 th and 28th day after surgery. In this study, Hb could not be measured immediately after the surgery, which means that the boundaries between IO-EBL and D-EBL are blurred. In case $\mathrm{Hb}$ is measured immediately after the surgery, it will be possible to separate D-EBL from IO-EBL and to identify the time point when the blood loss is not influenced by anesthesia type.

As shown in Table 2, the two groups did not show a signi- 
ficant difference in POD $0-3 \mathrm{Hb} \mathrm{DR}$. However in Hct DR, they showed a significant difference. The results may be related to hemodynamic accuracies of $\mathrm{Hb}$ and Hct. Ordinarily, $\mathrm{Hb}$ and Hct are used as indexes for anemia. In the case of Hct, it is influenced by erythrocyte size, plasma volume and fluid status. Thus, in the case of hemodilution, $\mathrm{Hb}$ is more effective to monitor the degree of anemia [23]. Likewise in this study, there was significant intergroup difference in POD 0-3 Hb DR, which implies that $\mathrm{Hb}$ reflects hematologic states more accurately.

Andrews et al. [2] reported that the blood loss was higher in GA than in SA, but was not serious enough to transfuse blood. To conclude, it was not significant clinically. Likewise in this study, there were no statistically significant differences in transfusional frequency and transfusion volume (Table 1). Meanwhile, this study was conducted retrospectively on the basis of medical records, and it was problematic to separate blood transfusions from FHSC injections. Accordingly, a prospective study should be conducted with the same standards for FHSC injections and blood transfusions are required.

In conclusion, POD $0-1 \mathrm{Hb}$ DR was significantly lower in the group $S$ than in the group $\mathrm{G}$ anesthetized by sevoflurane. In POD 0 $-3 \mathrm{Hb} \mathrm{DR}$, however, there was no significant intergroup difference. IO-EBL and D-EBL were significantly lower in the group S, but in POD 1-EBL and POD 2-EBL, the groups did not show significant differences. Moreover, there were no significant differences from operative day to POD 2-EBL.

Taken together, it appears that SA is effective to reduce the blood loss during the c-sec and during the operative day, but that it is not different from GA two days after surgery.

\section{References}

1. Greenhill JP. Shall spinal anesthesia be used in obstetrics? Anesthesiology 1950; 11: 283-8.

2. Andrews WW, Ramin SM, Maberry MC, Shearer V, Black S, Wallace DH. Effect of type of anesthesia on blood loss at elective repeat cesarean section. Am J Perinatol 1992; 9: 197-200.

3. Gilstrap LC 3rd, Hauth JC, Hankins GD, Patterson AR. Effect of type of anesthesia on blood loss at cesarean section. Obstet Gynecol 1987; 69: 328-32.

4. Guay J. The effect of neuraxial blocks on surgical blood loss and blood transfusion requirements: a meta-analysis. J Clin Anesth 2006; 18: 124-8.

5. Richman JM, Rowlingson AJ, Maine DN, Courpas GE, Weller JF, Wu CL. Does neuraxial anesthesia reduce intraoperative blood loss? a meta-analysis. J Clin Anesth 2006; 18: 427-35.

6. Leveno KJ, Cunningham FG, Gant NF, Alexander JM, Bloom SL, Casey BM, et al. Williams manual of obstetrics. New York, McGrawhill. 2003, pp 192-4.
7. Bourke DL, Smith TC. Estimating allowable hemodilution. Anesthesiology 1974; 41: 609-12.

8. Munson ES, Embro WJ. Enflurane, isoflurane, and halothane and isolated human uterine muscle. Anesthesiology 1977; 46: 11-4.

9. Dogru K, Yildiz K, Dalgic H, Sezer Z, Yaba G, Madenoglu H. Inhibitory effects of desflurane and sevoflurane on contractions of isolated gravid rat myometrium under oxytocin stimulation. Acta Anaesthesiol Scand 2003; 47: 472-4.

10. Yamakage M, Tsujiguchi N, Chen X, Kamada Y, Namiki A. Sevoflurane inhibits contraction of uterine smooth muscle from pregnant rats similarly to halothane and isoflurane. Can J Anaesth 2002; 49: 62-6.

11. Eger El 2nd, Johnson BH. Rates of awakening from anesthesia with I-653, halothane, isoflurane, and sevoflurane: a test of the effect of anesthetic concentration and duration in rats. Anesth Analg 1987; 66: 977-82.

12. Turner RJ, Lambros M, Kenway L, Gatt SP. The in-vitro effects of sevoflurane and desflurane on the contractility of pregnant human uterine muscle. Int J Obstet Anesth 2002; 11: 246-51.

13. Wray S. Uterine contraction and physiological mechanisms of modulation. Am J Physiol 1993; 264: C1-18.

14. Yildiz K, Dogru K, Dalgic H, Serin IS, Sezer Z, Madenoglu H, et al. Inhibitory effects of desflurane and sevoflurane on oxytocininduced contractions of isolated pregnant human myometrium. Acta Anaesthesiol Scand 2005; 49: 1355-9.

15. Karsli B, Kaya T, Cetin A. Effects of intravenous anesthetic agents on pregnant myometrium. Pol J Pharmacol 1999; 51: 505-10.

16. Luo D, Wang QY, Huang W, Lü S, Kong GY. The effect of propofol on isolated human pregnant uterine muscles. Sichuan Da Xue Xue Bao Yi Xue Ban 2004; 35: 668-70.

17. Hood DD, Holubec DM. Elective repeat cesarean section: Effect of anesthesia type on blood loss. J Reprod Med 1990; 35: 368-72.

18. Yoo KY, Lee JC, Yoon MH, Shin MH, Kim SJ, Kim YH, et al. The effects of volatile anesthetics on spontaneous contractility of isolated human pregnant uterine muscle: a comparison among sevoflurane, desflurane, isoflurane, and halothane. Anesth Analg 2006; 103: 443-7.

19. Wong RP, Carter HB, Wolfson A, Faustin C, Cohen SR, Wu CL. Use of spinal anesthesia does not reduce intraoperative blood loss. Urology 2007; 70: 523-6.

20. Chaudhuri P, Banerjee GB, Mandal A. Rectally administered misoprostol versus intravenous oxytocin infusion during cesarean delivery to reduce intraoperative and postoperative blood loss. Int J Gynaecol Obstet 2010; 109: 25-9.

21. Wu LF, Liu Y, Ruan Y. Clinical study on prevention of postpartum hemorrhage of cesarean section using hemabat in high risk pregnant women. Zhonghua Fu Chan Ke Za Zhi 2007; 42: 577-81.

22. Wallis JP, Wells AW, Whitehead S, Brewster N. Recovery from postoperative anaemia. Transfus Med 2005; 15: 413-8.

23. Macdougall IC, Ritz E. The normal haematocrit trial in dialysis patients with cardiac disease: are we any the less confused about target haemoglobin? Nephrol Dial Transplat 1998; 13: 3030-3. 